\title{
Paraquat Poisoning in Children
}

\author{
BRIAN J. MCDONAGH and JOHN MARTIN \\ From Alder Hey Children's Hospital, Liverpool
}

\begin{abstract}
McDonagh, B. J., and Martin, J. (1970). Archives of Disease in Childhood, 45, 425. Paraquat poisoning in children. Four children with paraquat poisoning are described, with 2 fatalities. In one fatal case delay in treatment occurred as the nature of the ingested fluid was uncertain. A method for rapid detection of paraquat in the urine is referred to. The treatment of paraquat poisoning consists of immediate gastric lavage and forced osmotic diuresis.
\end{abstract}

Paraquat is a dipyridylium compound widely used as a weedkiller and marketed by Imperial Chemical Industries as a fluid commercial concentrate containing $20 \%$ paraquat under the trade name of 'Gramoxone', and in a granular form for domestic use containing 5\% paraquat marketed as 'Weedol'. It is only effective when sprayed on to the leaves of plants and is rapidly inactivated on contact with soil. Several cases of poisoning with paraquat have been reported by Bullivant (1966), Almog and Tal (1967), Campbell (1968), Oreopoulos et al. (1968), Kerr et al. (1968), and Matthew et al. (1968).

Most cases are due to accidental ingestion of the concentrate from bottles that have previously contained beverages. Occupational fatalities have not been reported, but ocular damage with extensive loss of conjunctival epithelium due to a splash in the eye has been reported (Cant and Lewis, 1968).

During the past year we have seen 4 children with accidental paraquat poisoning, and it is our purpose to describe these cases and outline diagnostic features and possible lines of treatment.

\section{Case Reports}

Case 1. An 8-year-old girl swallowed liquid paraquat from an unlabelled bottle. She immediately ejected some of the fluid, and a few hours later vomited. After a delay of two days, she developed an ulcerated mouth and pharynx and was admitted to her local hospital. Shortly afterwards she vomited bloodstained fluid and became oliguric. Her urine was found to contain large amounts of albumin and her blood urea was $170 \mathrm{mg} . / 100 \mathrm{ml}$. The next day she was transferred to Alder Hey Hospital. Her blood urea

Received 4 November 1969. was now $210 \mathrm{mg} . / 100 \mathrm{ml}$. Haemoglobin, white cell count, serum electrolytes, blood $p \mathrm{H}$, and liver function tests were normal. A 24-hour urine specimen contained $0.69 \mathrm{mg}$. paraquat. Oesophagoscopy was carried out and showed a severe oesophagitis, with extensive sloughing of epithelium. Gastrostomy was performed and antibiotics and steroids were given. Urinary output improved on the 6th day and over the next 9 days her blood urea fell to $46 \mathrm{mg}$./100 ml. Further 24-hour urine collections on the 9 th day and 15 th day contained $1.60 \mathrm{mg}$. and $0.17 \mathrm{mg}$. paraquat, respectively. On the 12th day she became dyspnoeic and cyanosed. Her chest $x$-ray showed some generalized shadowing in both lung fields. Her condition continued to deteriorate and continuous oxygen therapy became necessary. On the 23rd day of her illness tracheostomy was performed and mechanical ventilation started. She died the following day.

Abnormal post-mortem findings were confined to the lungs and kidneys. The lungs were uniformly rubbery with a faint nodulation on firm compression. They were greyish red in colour. Histology showed extensive proliferation of bronchiolar epithelium and fibrosis throughout the lungs, extending to obliterate the majority of the alveoli. There was patchy round cell infiltration and recent intra-alveolar haemorrhage. The kidneys showed recovery stages following tubular necrosis. The liver was normal.

Post-mortem material was analysed for paraquat but none was found.

Case 2. This 2-year-old girl was taken to a Casualty Department with a history of having been found eating 'Weedol' granules approximately 10 minutes previously. An estimated $10 \mathrm{~g}$. 'Weedol' was missing from the container. Gastric lavage was carried out promptly and she was transferred to Alder Hey Hospital where forced diuresis was started within 3 hours of ingestion. Urine was collected in 2-hourly aliquots and the first specimen contained $80 \mathrm{\mu g}$. paraquat per litre, the 4-6-hour specimen contained $60 \mathrm{\mu g}$. per litre, and 
the 12-14-hour specimen was negative. Forced diuresis was continued for a total of 24 hours. She was observed for a total of 4 weeks during which time respiratory, renal, and hepatic function remained normal. She was subsequently well on follow-up.

Case 3. A 4-year-old girl drank an unknown quantity of purple fluid from a bottle found in a field near her home. She vomited half an hour later and repeatedly over the next few hours. 4 hours after ingestion she was taken to her local hospital. The remaining fluid was kept and sent for analysis. A preliminary report stated that it was a neutral fluid containing glucose and chloride. The child was admitted and soon complained of abdominal pain and passed an offensive stool. Gastro-intestinal symptoms continued for 48 hours, and she developed extensive ulceration of the mouth and lips. On the 4th day she was transferred to Alder Hey Hospital where apart from ulcerated lesions of the mouth and lips, the only abnormal clinical feature was oliguria. Her blood urea was $282 \mathrm{mg} . / 100 \mathrm{ml}$. On the sixth day the Analytical Laboratory reported that the ingested fluid was paraquat and a sample of urine taken that day contained $0.3 \mathrm{mg} . / 100 \mathrm{ml}$. of paraquat. Hydrocortisone therapy was started. The following day jaundice was noticed and the maximum bilirubin level reached $6 \cdot 1 \mathrm{mg} . / 100$ $\mathrm{ml}$. on the 8th day. A chest $x$-ray on the 8 th day showed diffuse shadowing in both lung fields, and clinically she became dyspnoeic and cyanosed. Over the next few days her urinary output improved, her blood urea fell to normal levels, and the jaundice cleared. A repeat chest $x$-ray on the 11th day showed an increase in pulmonary shadowing. 2 days later, after a period of clinical improvement, her condition deteriorated. She developed a rapid respiratory rate and increasing cyanosis not relieved by oxygen. She died on the 13th day after ingestion of paraquat.

At necropsy similar changes were present in the lungs and kidneys as in Case 1 , but of a different age. In addition there was sloughing of the epithelium of the tongue and upper oesophagus, and in the liver centrilobular biliary stasis.

Case 4. A 3-year-old boy was brought to the Casualty Department with superficial burns of his right thigh and hands. 24 hours previously he had been found playing in a shed on his father's farm where he had removed the stopper from a container of 'Gramoxone'. He had spilled some over his clothes and on to the floor and was playing beside a pool of the spilled fluid. He was a thumb-sucker and his hands were muddy at the time. He was immediately bathed and his clothing changed, but 6-8 hours later an erythematous rash appeared on his thigh and hands. When seen in the Casualty Department he had a large first degree burn on the anterior aspect of his thigh, and raised erythematous areas on the dorsum of his hands. There were no lesions in his mouth and he was otherwise well. Forced osmotic diuresis was started at once and urine collected in 2-hourly aliquots. The specimen contained $10.5 \mathrm{\mu g}$. paraquat and in this small amount, forced osmotic diuresis । continued after 24 hours. A urine sample c 48 hours after contact with paraquat conta $\mu \mathrm{g} . / 100 \mathrm{ml}$. of paraquat. As there was never ulceration, these findings suggest percutaneous tion. Observation over the next three weeks no evidence of hepatic, renal, or respiratory dist and on follow-up he has remained well. The his thigh remained superficial, responded to $\mathrm{cc}$ tive treatment, and in four weeks had completely

\section{Discussion}

Of our 4 patients 2 (Cases 1 and 3) fo closely the reported pattern in fatal cas first there was vomiting, and after a delay of $t$ signs of corrosive effect in the mouth and $\mathrm{pl}$ Subsequent evidence of hepatic and renal is ment appeared and finally the irreversibl changes. In Case 3 no specific treatmes started due to delay in identification of the it fluid. A similar delay could be avoided method for rapid detection of paraquat and in gastric aspirate and urine (Kerr et al., were employed when the nature of an ingeste is not known. Both these cases illustra relatively symptom-free period which occu the initial vomiting. This period may we to delay in instituting necessary therapy.

In Case 2 no outward effects were noted. may have been due to the relatively small a of paraquat ingested, or alternatively to the I treatment this child received. She weighed and may have taken $500 \mathrm{mg}$. paraquat, a certainly in excess of an estimated fatal $d$ $4 \mathrm{mg}$./kg. body weight (Almog and Tal, 196:

In Case 4 percutaneous absorption via the lesion almost certainly occurred. This $h$ previously been described in man though it similar to the situation described in rabbits । McElligot, and Hurst, 1966).

Paraquat is poorly absorbed from the $g$ mainly excreted in the urine, most being ex in the first 24 hours (Daniel and Gage, It appears that if a certain concentration of $\mathrm{pa}$ is reached for a short time in the lungs an irrev process is initiated and any subsequent therar no avail. As there is at present no certain ledge of the amount of ingested paraquat th cause the typical lesions in man, the best prc for successful treatment lie in the removal fr inactivation of, any paraquat in the stomach a rapid removal from the body of any alreac sorbed. Urgent gastric lavage should be perfic 
if possible using a $1 \%$ solution of bentonite, ${ }^{\star}$ a compound having a similar particulate composition to that of soil which is known to inactivate paraquat (Leeds Poisons Centre-personal communication).

Forced osmotic diuresis should then be started as soon as possible. Kerr et al. (1968) have shown this procedure promotes excretion of paraquat in the urine even when the serum levels are low. Haemodialysis has been suggested until paraquat is no longer detected in the serum (Matthew et al., 1968). It must be doubtful whether this would be more efficient than forced osmotic diuresis in view of the high levels rapidly obtained in the urine by this latter method.

Steroids and immunosuppressive drugs have been tried in the management of established paraquat poisoning (Bullivant, 1966; Duffy and O'Sullivan, 1968; Fennelly, Gallagher, and Carroll, 1968), but there is no convincing evidence of benefit from their use. The typical paraquat histological lesions were found in the transplanted lung of a patient on therapy with steroids, 6-mercaptopurine and azathioprine from before the time of transplant

^Bentonite (B.P.) is a native colloidal hydrated aluminium silicate which is an ingredient of calamine lotion and is available in most hospital pharmacies. To prepare the suspension $70 \mathrm{~g}$. bentonite are mixed with $100 \mathrm{ml}$. glycerine and made up to a litre with water. As the suspension takes up to 24 hours to settle, it should be prepared in advance and kept as part of routine Casualty Dept. stock. If possible it is recommended that the materials should be sterilized to eliminate any possible hazard from the presence of bacterial spores. The recommended volume for washout is $500 \mathrm{ml}$.
(Matthew et al., 1968), again indicating their ineffectiveness in this condition, even when used from the onset of exposure to paraquat.

We wish to thank Dr. E. G. Hall for his help in preparing this paper, and Dr. R. S. Jones and Dr. R. McL. Todd for permission to publish details of their cases.

\section{REFERENCES}

Almog, C., and Tal, E. (1967). Death from paraquat after subcutaneous injection. British Medical fournal, 3, 721.

Bullivant, C. M. (1966). Accidental poisoning by paraquat: report of two cases in man. British Medical fournal, 1, 1272.

Campbell, S. (1968). Death from paraquat in a child. Lancet, $1,144$.

Cant, J. S., and Lewis, D. R. H. (1968). Ocular damage due to paraquat and diquat. British Medical fournal, 3, 59.

Clark, D. G., McElligott, T. F., and Hurst, E. W. (1966). The toxicity of paraquat. British fournal of Industrial Medicine, $23,126$.

Daniel, J. W., and Gage, J. C. (1966). Absorption and excretion of diquat and paraquat in rats. British fournal of Industrial Medicine, 23, 133.

Duffy, B. S., and O'Sullivan, D. J. (1968). Paraquat poisoning. Fournal of Irish Medical Association, 61, 97.

Fennelly, J. J., Gallagher, J. T., and Carroll, R. J. (1968). Paraquat poisoning in a pregnant woman. British Medical fournal, 3 , 722.

Kerr, F., Patel, A. K., Scott, P. D. R., and Tompsett, S. L. (1968). Paraquat poisoning treated by forced diuresis. British Medical Fournal, 3, 290.

Matthew, H., Logan, A., Woodruff, M. F. A., and Heard, B. (1968). Paraquat poisoning-lung transplantation. British Medical Fournal, 3, 759.

Oreopoulos, D. G., Soyannwo, M. A. O., Sinniah, R., Fenton, S. S. A., McGeown, M. G., and Bruce, J. H. (1968). Acute renal failure in case of paraquat poisoning. British Medical Fournal, 1, 749.

Correspondence to Dr. John Martin, Alder Hey Hospital, West Derby, Liverpool L12 2AP. 